\title{
MORPHOLOGY, PROLIFERATION AND APOPTOSIS OF THE INTESTINE AS WELL AS METABOLIC AND ENDOCRINE TRAITS IN PRETERM AND TERM CALVES
}

\author{
S. Bittrich, H.M. Hammon, and J.W. Blum
}

Div. of Nutrition and Physiology, Inst. of Animal Genetics, Nutrition and Housing, University of Berne, CH-3012 Berne, Switzerland.

A considerable number of calves is born prematurely. Morbidity and mortality of preterm calves are higher than of calves born at normal term. Besides insufficient functioning of the lungs, immaturities of the gastrointestinal tract (GIT) and of endocrine control of metabolism are thought to contribute to health problems. Because corresponding studies are lacking in preterm calves, we have tested the hypothesis that there are differences in maturation at birth and in response to feeding for $8 \mathrm{~d}$ of the GIT and of metabolic and endocrine traits between term and preterm calves. Fourteen calves were born on $\mathrm{d} 275$ of gestation, i.e. $42 \pm 3 \mathrm{~h}$ after dams were injected $0.5 \mathrm{mg}$ prostaglandin $\mathrm{F}_{2 \alpha}$ and $5 \mathrm{mg}$ Flumethason, and were slaughtered either on $\mathrm{d} 1(\mathrm{GrPS}, \mathrm{n}=7)$ or on $\mathrm{d} 8(\mathrm{GrPF}, \mathrm{n}=7)$ of life. Another 14 calves, serving as control, were spontanously born after normal lengths of pregnancy $(290 \pm 2 \mathrm{~d})$ and were slaughtered either on $\mathrm{d} 1(\mathrm{GrNS}, \mathrm{n}=7)$ before first feeding or on $\mathrm{d} 8$ (GrNF, $\mathrm{n}=7$ ) of life. The $8 \mathrm{~d}$ old preterm and term calves were fed colostrum and then mature milk. Blood samples were taken from jugular veins to measure blood gases, hematologic, metabolic and endocrine traits. Histomorphometrical analyses of duodenum, jejunum, ileum and colon were performed on slides stained with hematoxilin and eosin. Cell proliferation was based on counting crypt cells which (following injection of $500 \mu \mathrm{g} 5$-bromo-2 ${ }^{2}$-deoxyuridine $1 \mathrm{~h}$ before slaughter) had incorporated this substance into DNA and relative to unlabeled epithelial cells and as relative to the length of the mucosal epithelial layer. Apoptotic cells were visualized based on terminal transferase 3 ' end labelling by fluorescence microscopy. Results: The $\mathrm{pH}$ was lower $(\mathrm{P}<0.05)$ in GrPS than in GrPF. Mean $\mathrm{pCO}_{2}$ tended to be higher $(\mathrm{P}<0.05)$ in GrPS versus GrNS, and tended to be higher $(\mathrm{P}<0.1)$ in GrPS than in GrPF. There were no group differences in $\mathrm{pO}_{2}$, base excess, $\mathrm{HCO}_{3}, \mathrm{TCO}_{2}$, and $\mathrm{sO}_{2}$. Haematological traits were always in physiological range and barely differed between term and preterm calves. Blood plasma concentrations of metabolites (protein, immunoglobulin G, albumin, urea, creatinine, nonesterified fatty acids, triglycerides, cholesterol, glucose, lactate) and hormones (growth hormone, insulin-like growth factor-1, 3.5.3'-triiodothyronine and thyroxine, cortisol, insulin, glucagon) and patterns of postnatal changes in preterm calves were in the same range as in calves born at normal term. In jejunum villus circumferences, areas and heights were greater $(\mathrm{P}<0.001)$ in GrNS than in GrNF and GrPS. Villus circumferences and villus heights in ileum were greater $(\mathrm{P}<0.05)$ in GrNS than in GrNF. Crypt depths in duodenum, jejunum, ileum and colon were greater $(\mathrm{P}<0.001)$ in GrNF than in GrNS and GrPF. Villus circumferences, areas and heights were greatest in jejunum, whereas colon had the greatest crypt depths. Number of BrdU-labeled cells in duodenum and jejunum were higher $(\mathrm{P}<0.05)$ in GrNF than in GrNS. Number of BrdU-labeled cells in duodenum and number of BrdUlabeled cells per length in jejunum were higher $(\mathrm{P}<0.01)$, as well as number of BrdU-labeled cells per length in ileum tended to be higher $(\mathrm{P}<0.1)$ in GrNF than GrPF. Apoptotic cells were present in the submucosa (including Peyer Patches), but no small gut epithelial apoptic cells were detectable. However, it was surprising that GrNS had greater villi than GrNF, whereas GrNF had highest 
epithelial proliferation rates. The much greater crypt depths in GrNF than GrNS indicated that crypt depth was more markedly affected by feeding than villus height in the mature intestine, but preterm calves did not show these effect. In conclusion, calves born $2 \mathrm{wk}$ before normal term are basically able to sucessfully control their metabolism and their endocrine patterns as normal term calves. However, the intestinal tract in preterm calves is immature and the reaction to feed ingestion was reduced, even though preterm calves were obviously able to utilize ingested nutrients.

\title{
BUCKET-FED, AUTOMATE-FED AND CALVES SUCKLING ON THEIR DAMS: EFFECTS OF FEEDING COLOSTRUM AND MILK WITH DIFFERENT FREQUENCY AND INTENSITY
}

\author{
H. M. Hammon, A. L. Nussbaum A. L., G. Schiessler, and J. W. Blum.
}

Div. of Animal Physiology and Nutrition, Inst. of Animal Genetics, Nutrition and Housing, University of Berne, CH-3012 Berne, Switzerland

Colostrum (C) provides high amounts of nutrient and non-nutrient substances, which are important for health and development of neonatal calves. To study the effects of different feeding frequency and intensity of $\mathrm{C}$ and milk on growth performance, metabolic and endocrine traits during the first month of life calves ( $n=7$, respectively) were fed twice daily by bucket (GrBR), restricted amounts (GrAR; pair-fed with GrBR) or unlimited amounts (GrAL) several times per d with an automate, or were suckling their dams (GrSL). Calves fed by bucket or automate received $\mathrm{C}$ powder for $3 \mathrm{~d}$, then milk powder ( $\mathrm{d} 4 \mathrm{-d} 14$ ) and milk up to $\mathrm{d} 28$. In groups fed by automate software was available to continuously register the time points and amounts of ingested feed up to the age of $11 \mathrm{~d}$. Body weight (BW) was measured immediately after birth and then once weekly. Blood samples were taken on d 1, 2, 3, 7, 14, 21 and 28 after birth. Plasma concentrations of total protein (TP), IgG, albumin, urea, glucose, NEFA and triglycerides were measured photometrically. Plasma concentrations of insulin, glucagon and insulin-like growth factor-I (IGF-II) and growth hormone (GH) were measured by radioimmunoassay. Data were evaluated by analysis of variance using a mixed model with treatment and time as fixed effects and the individual calves as random effects. Preprandial triglyceride concentrations on $\mathrm{d} 7$ were higher $(\mathrm{P}<0.05)$ in GrAR than in GrBR. Insulin concentrations on $\mathrm{d} 7$ tended to be higher $(\mathrm{P}<0.1)$ in GrAR than in GrBR. Concentrations of GH on $\mathrm{d} 7$ were higher $(\mathrm{P}<0.05)$ from 120 to $140 \mathrm{~min}$ and were lower $(\mathrm{P}<0.05)$ from 240 to $360 \mathrm{~min}$ after start of feeding in GrAR than GrBR. Concentrations of IGF-I were higher $(\mathrm{P}<0.05)$ on $\mathrm{d} 7,14$, and 28 in GrAR than in GrBR. There were no significant differences in growth performance during the first month of life compared with GrBR. In GrAL dry matter intakes and meal sizes per visit were higher $(\mathrm{P}<0.05)$, but total visits (with and without milk intake) at the automat were lower $(\mathrm{P}<0.05)$ than in GrAR. Feed intake in GrAL increased $(\mathrm{P}<0.05)$ up to $\mathrm{d} 4$, then remained stable and was always higher $(\mathrm{P}<0.05)$ than in GrAR. Weight gain was greater $(\mathrm{P}<0.05)$ in GrAL than GrAR in wk 1 , but metabolic and endocrine differences were small in the first week of life. In GrSL concentrations of TP and IgG were higher (P $<0.05)$ during the whole study and albumin concentrations were higher $(\mathrm{P}<0.05)$ in the first 2 wk 
of life than in GrAL. Urea concentrations were lower $(\mathrm{P}<0.05)$ on d 3 and 21 in GrSL than in GrAL. On d 3, triglyceride, glucose and insulin concentrations were higher $(\mathrm{P}<0.01)$, whereas concentrations of glucagon and GH were lower $(\mathrm{P}<0.05)$ in GrSL than in GrAL. Growth performance during the first three weeks of life was comparable in GrAL and GrSL, and only slightly increased in GrSL at the end of the first month of life. In conclusion, high feeding frequency and suckling improved the metabolic and endocrine status, but barely affected growth performance. In contrast, unlimited feed intake at the automat enhanced growth performance, but barely influenced the metabolic status.

\title{
THE EFFECT OF INCREASING UREA INTAKE IN THE LACTATING DAIRY COW ON FOLLICULAR DYNAMICS AND OVULATION
}

\author{
Laven RA, Biggadike HJ, Collins CA
}

ADAS Bridgets Dairy Research Centre, Martyr Worthy, Hants SO21 1AP

This study was designed to investigate the effect of increasing the intake of QDN (in the form of urea) on the follicular dynamics of lactating dairy cows. Forty-two Holstein cows were selected from the ADAS Bridgets herd using inclusion criteria of third or subsequent lactation, calved in the previous 16 weeks and deemed suitable for re-breeding following veterinary examination. They were randomly allocated to one of two diets, control or high QDN. The control diet was based on maize and grass silage and fed as a TMR once daily, except for a sugar beet feed $(2 \mathrm{~kg} / \mathrm{cow} / \mathrm{d})$ which was fed to all cows separately on top of the ration in two equal feeds, after morning milking and after evening milking. It was formulated to meet metabolisable energy and metabolisable protein (ME \& MP) requirements for early lactation cows according to the UK ME and MP systems. The high QDN diet differed from the Control diet only in the inclusion of $250 \mathrm{~g}$ urea per cow/day, this was mixed with the supplemental sugar beet feed to overcome any palatability problems associated with feeding high levels of urea. All cows were fed the control diet for an initial acclimatisation period of 3 weeks prior to the study commencing. At the end of this period the cows were synchronised and the cows on the high QDN treatment had their diet changed to the high QDN specification. The diet of both groups then remained unchanged for the remainder of the study period

All cows were synchronised using an eight day progesterone/ $\mathrm{PGF}_{2 \alpha}$ protocol. Rectal scanning was undertaken by means of a B-mode ultrasound probe $(5 \mathrm{MHz})$ to measure follicular development. Cows were examined ten days before first insemination (the day of PRID ${ }^{\circledR}$ insertion), seven days later (the day of prostaglandin injection) and daily thereafter for a maximum of five days to monitor the timing of ovulation. Each scanning occasion was recorded on video for subsequent measurements of the number and size of follicles, corpora lutea and embryos. Follicles were classed as small $(<0.5 \mathrm{~cm}$ diameter) or large $(0.5 \mathrm{~cm}$ or greater diameter).

No significant effect of diet on the number and size of follicles or number and size of corpora lutea was found at any time $(\mathrm{P}>0.1)$, nor was there a significant effect of treatment on the timing of ovulation $(\mathrm{P}>0.5)$. This suggests that increases in QDN intake have no significant effect on follicular dynamics or ovulation if the QDN is increased at least ten days before insemination 